\title{
Materials Forming of Dolphin Model for Hydrodynamic Research Based on the 3D Printing Technology
}

\author{
Heng Zhang ${ }^{1}$, Jiajun Chen ${ }^{2, a^{*}}$, Zhe $\mathrm{Wu}^{2}$, Gucheng Zhu ${ }^{2}$, Zhiguo Zhang ${ }^{2}$ \\ ${ }^{1}$ Naval Academy of Armament, Beijing, 100161, China \\ ${ }^{2}$ School of Naval Architecture and Ocean Engineering, Huazhong University of Science and \\ Technology, Wuhan, 430074, China
}

Corresponding Author: ${ }^{\mathrm{a}^{*} 401024938 @ q q . c o m}$

\section{Keywords: 3D printing, Model, Bottlenose dolphin, Flexible, Rigid.}

\begin{abstract}
Traditional manufacturing techniques used for developing the models for hydrodynamic research are slow and costly. Based on the development of current technology, 3D printing technology could be the fastest way to generate the model for with high accuracy for experimental test. With the help of 3D printing technology, it would only take days or hours to generate the 3D model with complicated geometry. This paper presents the application of 3D printing method for dolphin model generation. Rigid and flexible dolphin 3D models are made with non-metallic. 3D printing parts include the outer mold and added stiffness to the model. The dolphin model is $1 \mathrm{~m}$ long, and does not have pectoral fin. The dolphin hydrodynamic model developed using 3D printing technology show promise in model development for future hydrodynamic model studies. A rigid model and two flexible models with different material have been built by 3D printing. The appropriate materials were chosen for flexible dolphin model, which have the similar properties with dolphin skin.
\end{abstract}

\section{Introduction}

3D printing technologies have been developed for the space program for long time. This technology also have many advantages in the hydrodynamic study, it is a robust, accurate, and affordable method to support different research for model developments. Model tests are widely used for force measurement, pressure measurement and dynamics to improve the design subjects. The model development for the test should be high accuracy, low cost and less time of model production [1]. 3D printing technology could also serve as the link between Computational Fluid Dynamic (CFD) simulations and experimental test, due to its high accuracy [2].

In tradition methods, it took months to manufacture models for hydrodynamic test. Most models were CNC machined from aluminum (for low speed) and steel (for high speed) tunnels or other materials. 3D printing results in a faster and better response to the designer's needs by permitting concurrent study of new concepts in the experimental study and via computer simulation. 3D printing is one of the rapid prototyping (RP), which can be referred to as solid free-form manufacturing computer automated manufacturing, and layered manufacturing [3]. The essence of 3D printing is that make a certain processing do a series of slice edit by computer software, and then generates a digital model file, based on the size of model using particular additive as adhesive materials, and using the particular forming equipment, which is 3D printer, to print out real and stereoscopic object finally. At present, the high performance grown-up 3D printing process including Stereo-lithography (SL), Selective Laser Sintering (SLS), and Fused Deposition Modeling (FDM) [4].

The Johns Hopkins University Applied Physics Laboratory (JHU/APL) [5] has been developing a technique to reduce the cost of building wind tunnel models. JHU/APL has built several models using this technique and tested them at subsonic and supersonic speeds. A study funded through an MSFC Center Director's Discretionary Fund (CDDF) project was undertaken to determine the feasibility of using models constructed from rapid prototyping materials using RP methods for preliminary aerodynamic assessment of future launch vehicle configurations. Around the world, Springer team of NASA [6], Aghanajafi [7] of Khajeh-Nasier Toosi university of technology in Iran, Landrum team [8] 
of Alabama university in the United States, Chuk team [9] of McGill university in Canada, and Azarov team [10] of Ts AGI in Russian, made correlational studies as early as 1990s. And they proved the feasibility of the 3D printing technology used in wind tunnel test.

The dolphins are noted for small hydrodynamic drag, and a delay in the onset of boundary layer turbulence with increasing Reynolds number. In 1957 Kramer [11] suggested that a compliant biomaterial coating on the dolphin is responsible for the decreased drag, and drag reduction was reported during 1960-62 by Kramer for towed underwater bodies covered with coatings to simulate the dolphin skin. Based his views on observations of swimming dolphins, he sets his compliant coatings on the dolphin skin, as shown in Fig. 1. He identified the dermal ridges and papillae of Fig. 1.

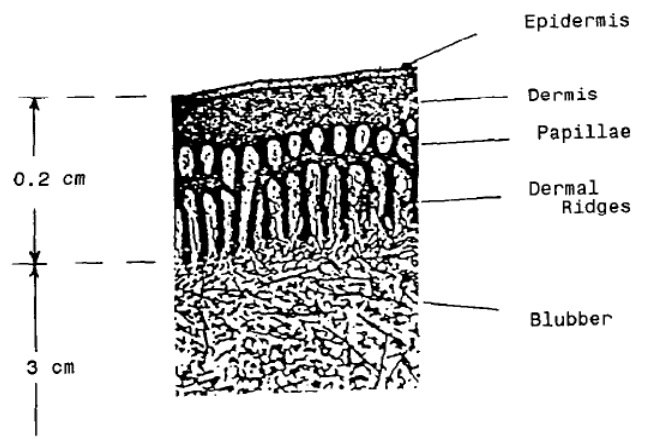

Fig. 1 Dolphin skin structure. [11]

The skins of cetacean are usually smooth, but dolphin's skin has many dermal ridges. The dermal ridges form into crest at dermal papilla. Integrated investigation of different whale dermal ridge, the interval between dermal ridges is $0.41-2.35 \mathrm{~mm}$, the height is $7-114 \mathrm{~mm}$.

In this paper, dolphin model for hydrodynamic study have been produced with different material, as rigid and flexible. The study chose the appropriate materials for flexible dolphin model, which have the similar properties with dolphin skin. Finally, a rigid model and two flexible models with different material have been built by 3D printing, and this paper discussed the advantages and limitations in the process of model forming.

\section{Original Dolphin Model}

In order to make the model, accurate measurements of Oossanen [12] were taken of full-grown female specimen of a Florida bottle-nosed dolphin, Tursiops truncatus, which had been caught in the Gulf of Mexico off Florida Keys. Fig. 2 shows the dimensions of the body and the cross-sections of the body, the tail, and the dorsal fin.

The main dimensions and shape of the dolphin model is the same as Oossanen's data, and according to the scale proportionate change the length as $1 \mathrm{~m}$, as this approach would make the simulation and test results more comparable. Table 1 gives the main dimensions of dolphin.

Table 1. Dimensions of dolphin, scale 1:1. [12]

\begin{tabular}{lc}
\hline Surface area of dolphin with tail and flippers & $1.891 \mathrm{~m}^{2}$ \\
Surface area of tail flukes & $0.171 \mathrm{~m}^{2}$ \\
Surface area of dorsal fin & $0.09 \mathrm{~m}^{2}$ \\
Displacement of dolphin with tail and fins & $100.629 \mathrm{dm}^{3}$ \\
Displacement of tail flukes & $1.830 \mathrm{dm}^{3}$ \\
Displacement of dorsal fin & $1.002 \mathrm{dm}^{3}$ \\
Position of centre of gravity of volume of dolphin with tail and flippers posterior to snout $0.909 \mathrm{~m}$ \\
Position of centre of gravity of volume of dorsal fin posterior to snout & $1.142 \mathrm{~m}$ \\
Length of dolphin as measured from tip of snout to posterior extremety of flukes & $2.322 \mathrm{~m}$ \\
Tip of snout to point of maximum thickness & $0.808 \mathrm{~m}$ \\
\hline
\end{tabular}



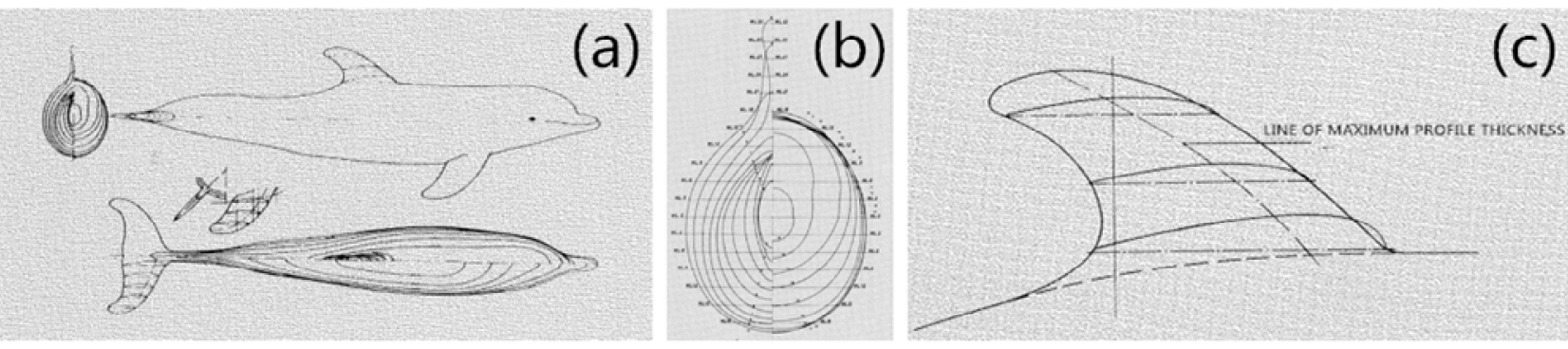

Fig. 2 Contours of the bottle-nosed dolphin. (a) body section; (b) cross sections; (C) dorsal fin [12].

\section{D Dolphin's Modeling}

In this paper, three-dimensional modeling software SolidWorks is applied to build the 3D dolphin model, whose data was provided by Oossanen. Fig. 3 shows the model in SolidWorks. The principal dimensions of dolphins models and the data in Table 1 after proportion scaling is identical. Oossanen's main purpose of this experiment was to investigate the dolphin resistance characteristics, so the model does not have the pectoral fin.

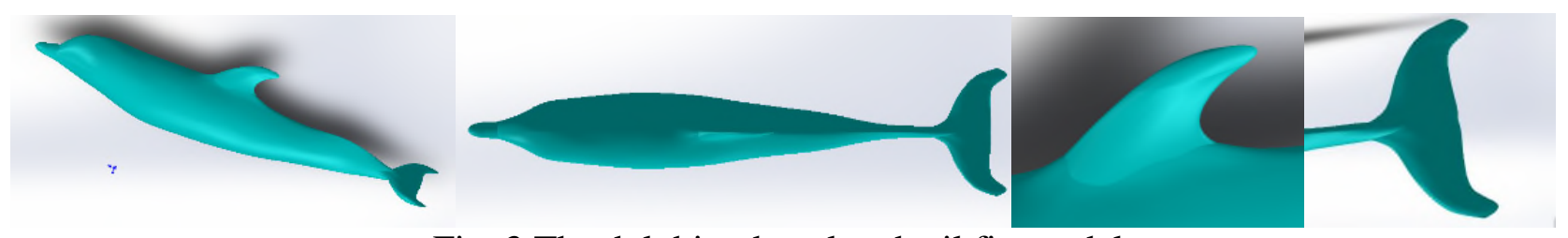

Fig. 3 The dolphin, dorsal and tail fin model.

\section{Rigid Model}

Materials. Epoxy resins are low molecular weight pre-polymers or higher molecular weight polymers which normally contain at least two epoxide groups. The epoxide group is also sometimes referred to as a glycidyl or oxirane group.

An important criterion for epoxy resins is the epoxide content. This is commonly expressed as the epoxy equivalent weight, which is the number of epoxide equivalents in $1 \mathrm{~kg}$ of resin (Eq./kg), or as the equivalent weight, which is the weight in grammes of resin containing 1 mole equivalent of epoxide $(\mathrm{g} / \mathrm{mol})$. One measure may be simply converted to another:

Equivalent weight $(\mathrm{g} / \mathrm{mol})=1000 /$ epoxide number $(\mathrm{Eq} . / \mathrm{kg})$.

Method. Since appearance of the dolphin is more complicated, using the traditional machining is hard to guarantee precision of bionic and has the high cost. While $3 \mathrm{D}$ printing has $0.1 \%$ forming accuracy, the 3D printer that is developed independently by HUST and its schematic are shown as Fig. 4. The model uses epoxy resin as printed material, products of which have high precision, and have certain rigidity and hardness.
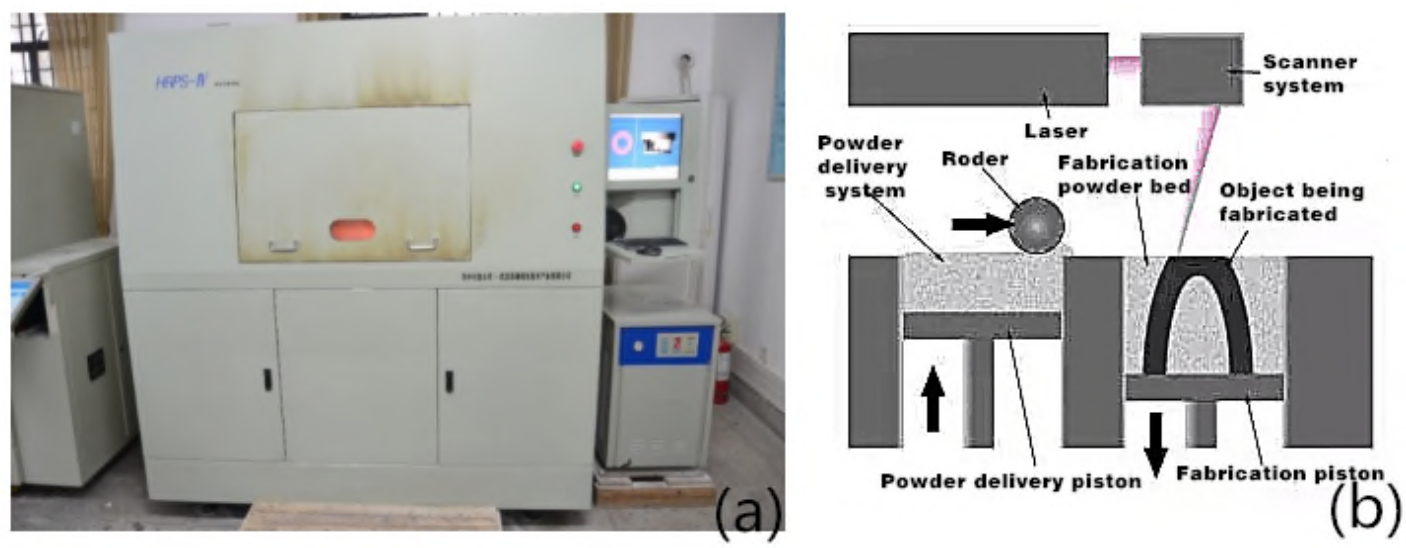

Fig. 4 (a) 3D printer; (b) Schematic diagram of 3D printing. 
Being limited by the length and installation of internal sensor, dolphin is divided into three sections when printing. Dolphin's each section connect by a steel rectangular tube $(20 * 30)$ whose thickness is $3 \mathrm{~mm}$, it can prevent the segmented from lateral rotation at the same time. Fig. 5 (a) is components of $3 \mathrm{D}$ printing completed rigid model and (b) is assembled rigid model, and (c) is the rigid model in test channel.
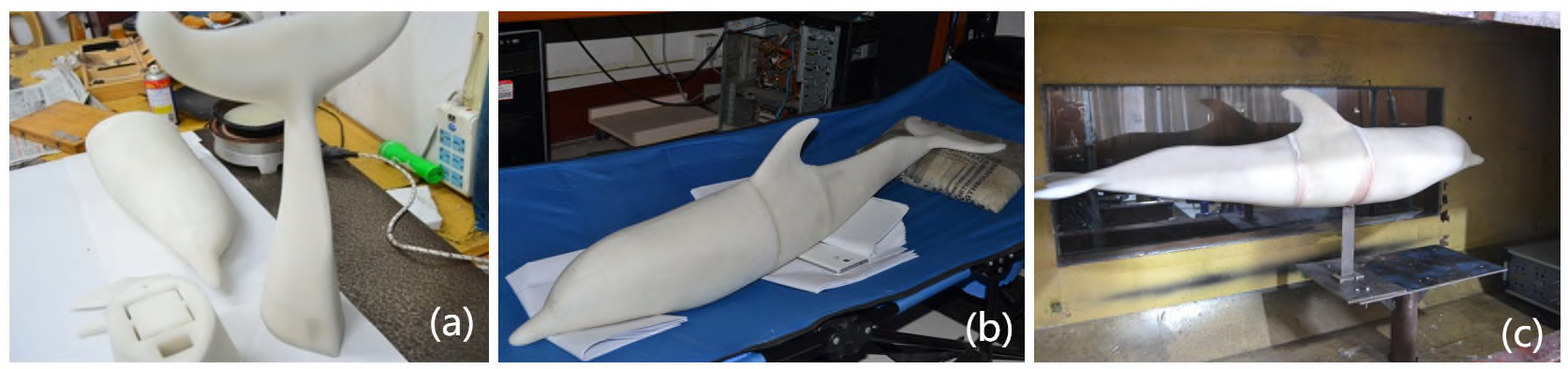

Fig. 5 (a) Components of rigid dolphin model; (b) Assembled rigid dolphin model; (c) the rigid model in test channel.

\section{Flexible Model.}

Materials. Due to the particularity of the silicone material, the model cannot use the traditional casting mold, and the epoxy resin and silicone don't react. Hence, this paper finally uses the method of 3D printing mold, for silica gel casting. Generally it should comply with the following conditions when the flexible material has been selected: density close to water, impermeable, Shear modulus is similar to water dynamic pressure. The density of silica gel is $1000 \mathrm{~kg} / \mathrm{m}^{3}$, which is the most close to the flexible skin in common material.

Table 2. Typical properties of Dow corning silicone T-4.

\begin{tabular}{|c|c|c|}
\hline Property & Unit & Value \\
\hline \multicolumn{3}{|l|}{ Base } \\
\hline Viscosity & $\mathrm{cp} / \mathrm{mPa} . \mathrm{s}$ & 70000 \\
\hline Specific gravity & & 1.1 \\
\hline \multicolumn{3}{|c|}{ XIAMETER Curing Agents RTV-4234-T4 or RTV-4234-T4 O } \\
\hline Viscosity & $\mathrm{cp} / \mathrm{mPa} . \mathrm{s}$ & 300 \\
\hline Specific gravity & & 0.96 \\
\hline \multicolumn{3}{|c|}{ Base and Curing Agent mixture (100:10 by weight) } \\
\hline Mixed viscosity & mPa.s & 35000 \\
\hline Working time at $23^{\circ} \mathrm{C}\left(73.4^{\circ} \mathrm{F}\right)$ & minutes & 90 \\
\hline Curing Time & hours & 12 \\
\hline \multicolumn{3}{|c|}{ Cured for 24 hours at $23^{\circ} \mathrm{C}\left(73.4^{\circ} \mathrm{F}\right)$ with XIAMETER RTV-4234-T4 Curing Agent } \\
\hline Hardness(Shore A) & & 40 \\
\hline Tenslie strength & psi & 971 \\
\hline Tenslie strength & mPa.s & 6.7 \\
\hline Elongation at break & $\%$ & 400 \\
\hline Tear strength;Die B & ppi & 150 \\
\hline Tear strength & $\mathrm{N} / \mathrm{mm}$ & 27 \\
\hline \multicolumn{3}{|c|}{ Cured for 24 hours at $23^{\circ} \mathrm{C}\left(73.4^{\circ} \mathrm{F}\right)$ with XIAMETER RTV-4234-T4 O Curing Agen } \\
\hline Hardness(Shore A) & & 40 \\
\hline Tenslie strength & psi & 942 \\
\hline Tenslie strength & mPa.s & 6.5 \\
\hline Elongation at break & $\%$ & 375 \\
\hline Tear strength; Die B & ppi & 180 \\
\hline Tear strength & $\mathrm{N} / \mathrm{mm}$ & 32 \\
\hline
\end{tabular}


This study chooses Dow corning silicone of America, which type is T-4 and the hardness is 42A (properties of which is in Table 2), and ordinary medical silica gel of China, which the hardness is 40 and 30. Silica gel has good liquidity and stable physical properties, is convenient for casting.

Method.
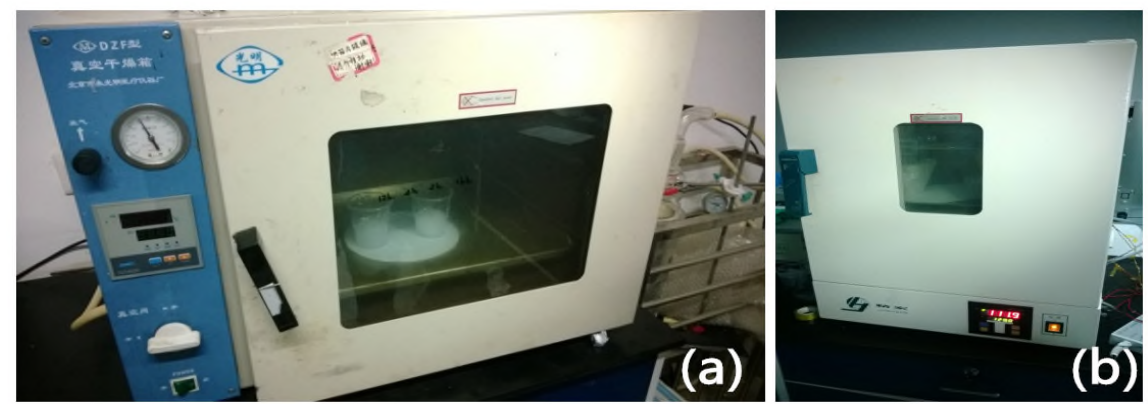

Fig. 6 (a) is silica gel mixture in the vacuum chamber and (b) is drying oven.

The silicone and curing agent are mixed in 10:1, the entire process is on the balance to ensure the accuracy of dosage. In order to prevent the silicone $\mathrm{AB}$ liquid mixed from air bubbles in the process of mixing, this study puts the solution that is obtained into vacuum drying chamber to deaerate after stirring it, which shown as Fig. 6 (a). It has to be attention that does not make the fluid height too high in the container, because that would prevent bubbles emerging. Putting the mixture into the drying oven (Fig. 6 (b)) and heating up to accelerated curing after deaeration completed, solidification of silica gel takes about 20 minutes under 120 degrees Celsius. Deaeration process is very important, the Fig. 7 (a) and (b) are the comparison of model material that has obtained deaeration and not, which (a) is obtained deaeration and (b) is not, and (c) is the caudal fin model.
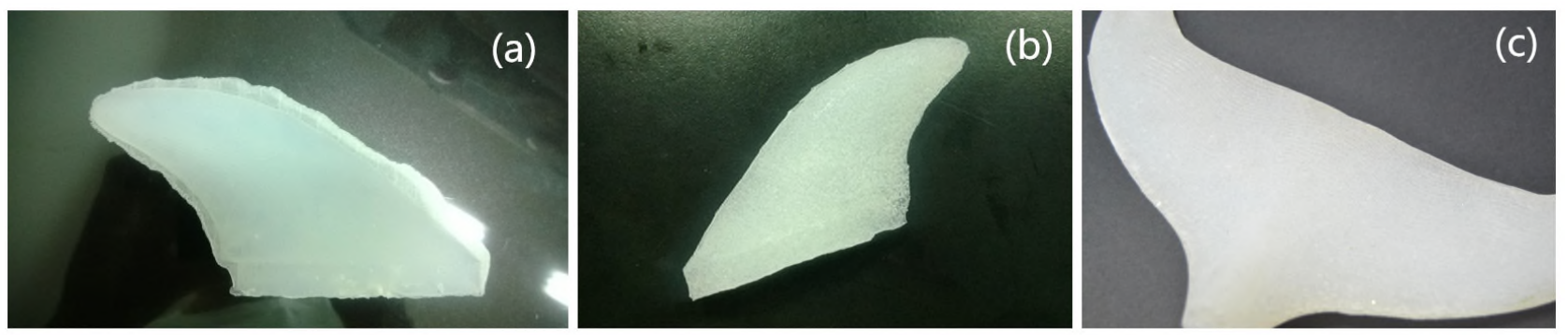

Fig. 7 Dolphin flexible dorsal fin and caudal fin models.

Deaeration is the most time consuming in the casting process, therefore, in the beginning, using silica gel that is not deaeration and silica gel that is deaeration to cast dolphin dorsal fin model at the same time, to observe the physical properties of the finished products. The results showed that surface has not deaerated is rough and has many small pit, it mainly because the interface of silica gel solution and mould has plenty of air bubbles. Bubbles become into the small pit after forming. There are many visible air bubbles inside the silica gel, which remain due to viscidity of silicone, this will result in a certain destruction to physical properties of the silicone. While inside of the dorsal fin, after deaeration, is homogeneous and has no air bubbles, and surface is flat enough, it has the better physical properties. Therefore, even though deaeration is time costing, it cannot be omitted.
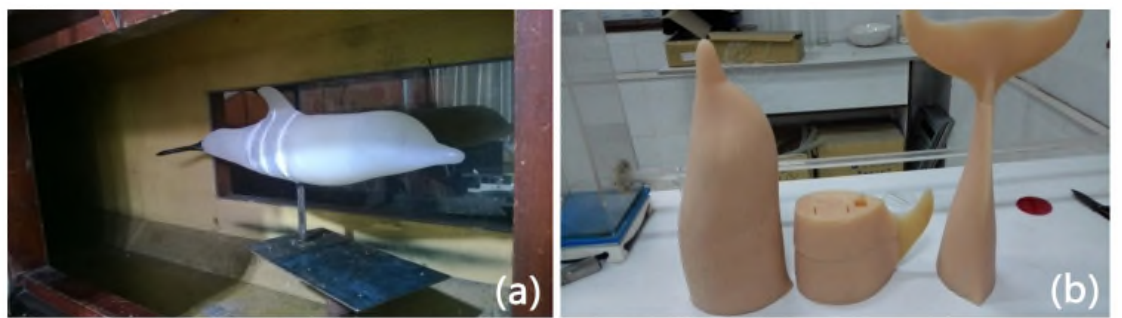

Fig. 8 (a) The flexible model of Dow corning silicone mounted in test channel; (b) The flexible model of ordinary medical silica gel. 
It is worth mentioning that we should spray a layer of mold release agent evenly in mould before casting. The stripper uses oily demould agent, especially for rubber, metal, glass and other industrial products to demould, and it can improve lubrication and anti-corrosion properties of the mould at the same time. Silica gel and mould stripping need to impose a certain external force before using the demould agent, the force require, after spraying mold release agent, greatly reduced, this makes the demoulding quick and convenient. Fig. 8 is completed flexible models.

\section{Conclusions}

3D printing method has been shown to be feasible in their limited direct application to hydrodynamic testing for producing preliminary model. The accuracy between $3 \mathrm{D}$ printing and modeling by 3D software is extremely high. This makes hydrodynamic testing more affordable for small programs with low budgets and for educational purposes. It can be concluded from this study that models constructed using 3D printing method and materials can be used in dolphin hydrodynamic testing. The accuracy of the data is lower than that of a metal model due to surface finish and dimensional tolerances, but is quite accurate for this level of testing. In addition, the methods used in this model development will be applied to the next model to further improve the efficiency of the design and manufacturing process.

\section{References}

[1] S. Daneshmand, R. Adelnia, S. Aghanajafi, Evaluating Aerodynamic Characteristics of Wind-Tunnel Models Produced by Selective Laser Sintering Method, Proceedings of the 4th WSEAS International Conference on Fluid Mechanics and Aerodynamics, Elounda, 2006, pp.12-17.

[2] C. Tyler, W. Braisted, J. Higgins, Evaluation of Rapid Prototyping Technologies for Use in Wind Tunnel Model Fabrication, 43rd AIAA Aerospace Sciences Meeting, Reno, Nevada, 2005.

[3] A. M. Springe, Application of Rapid Prototyping Methods to High-Speed Wind Tunnel Testing, NASA/TP, 1998.

[4] L. Bechthold, V. Fischer, A. Hainzlmaier, et al. A Qualitative Assessment of Applications, Recent Trends and the Technology's Future Potential, Studien zum deutschen Innovations system Nr, 2015, pp. 17-2015.

[5] R. J. Hildebrand, R. C. Eidson, C. Tyler, Development of a Low Cost, Rapid Prototype Lambda Wing-Body Wind Tunnel Model, 21st Appl. Aerodyn. Conf. Orlando, Florida, 2003, pp. 23-26.

[6] A. Springer, Evaluating aerodynamic characteristics of wind-tunnel models produced by rapid prototyping methods, J. Spacecraft Rockets, 35(6) (1998) 755-759.

[7] C. Aghanajafi, S. Daneshmand, A. A. Nadooshan, Influence of layer thickness on the design of rapid-prototyped models, J. Aircr. 46(3) (2009) 981-987.

[8] D. B. Landrum, R. M. Beard, P. A. La Sarge, et al. Evaluation of stereolithography rapid prototyping for low speed airfoil design, AIAA, 1997.

[9] R. N. Chuk, V. J. Thomos, A comparison of rapid prototyping techniques used for wind tunnel model fabrication, Rapid Prototyping J. 1998, pp. 185-196.

[10] Y. A. Azarov, et al, Experience in laser stereolithography and its application in manufacturing wind-tunnel aerodynamic models of various purposes, Suzdal, Russia: SPIE, 4(4) (2002) 433-440.

[11]M. O. Kramer, Boundary Layer Stabilization by Distributed Damping, Amer. Soc. Nav. Eng. 72(1) (1960) 25-33.

[12]I. P. V. Oossanen, Hydrodynamic Resistance Characteristics of Humans Dolphins and Ship Forms, Brit. Maritime Technol. 24 (1988) 501-509. 